\title{
Customer Cohort Climate: A Conceptual Model for Group Service Encounters: An Abstract
}

\author{
Linda W. Lee, Ian P. McCarthy, and Debbie Ellis
}

\begin{abstract}
Group service encounters, when multiple customers are intentionally batched and involved in the delivery and consumption of a service, are common in tourism and hospitality, recreation, and education. In such service settings, customers will accept, expect, and sometimes even desire to share and consume the service experience "with" other customers. Thus, in group service encounters, customer-tocustomer interactions are often integral to the service being provided.

While previous research has largely examined services that take place between a single customer and a service employee or where customers consume "in the presence of" other customers, the topic of consuming "with" other customers has not been fully explored. This theory development paper focuses on understanding how the characteristics of the group itself impacts how group service encounters should be designed and delivered.

This paper introduces the concept of customer cohort climates (CCCs) and explores how CCCs vary and the implications for the design of group service encounters. To understand how CCCs vary, we focus on two fundamental dimensions: why consumers participate in a group service encounter and how they interact with each other. More specifically, we develop a typology that shows how CCCs vary according to whether the service employee or the customer is the protagonist that initiates customer-to-customer interactions and customers' hedonic or utilitarian motivation.
\end{abstract}

References Available Upon Request.

\author{
L.W. Lee $(\bowtie)$ \\ Royal Institute of Technology (KTH), Stockholm, Sweden \\ e-mail: linda.lee@ strategexconsulting.com \\ I.P. McCarthy \\ Simon Fraser University, Vancouver, Canada \\ e-mail: ian_mccarthy@sfu.ca \\ D. Ellis \\ Royal Institute of Technology (KTH), Stockholm, Sweden \\ University of KwaZulu-Natal, Scottsville, South Africa \\ e-mail: vigard@ukzn.ac.za
}

